\section{OPEN ACCESS}

Edited by:

Rahul K. Nath,

Texas Nerve and Paralysis Institute,

United States

Reviewed by:

Jeffrey B. Friedrich,

University of Washington,

United States

Scott Ferris,

The Alfred Hospital, Australia

*Correspondence:

Lukas Rasulic

lukas.rasulic@gmail.com

Specialty section:

This article was submitted to

Neurosurgery,

a section of the journal

Frontiers in Surgery

Received: 11 September 2021 Accepted: 22 November 2021

Published: 16 December 2021

Citation:

Rasulić L, Djurašković S, Lakićević N,

Lepić M, Savić A, Grujić J, Mićić A,

Radojević S, Puzović V, Maletić M and

Mandić-Rajčević S (2021) Surgical

Treatment of Radial Nerve Injuries

Associated With Humeral Shaft

Fracture-A Single Center Experience.

Front. Surg. 8:774411.

doi: 10.3389/fsurg.2021.774411

\title{
Surgical Treatment of Radial Nerve Injuries Associated With Humeral Shaft Fracture-A Single Center Experience
}

\begin{abstract}
Lukas Rasulić ${ }^{1,2 *}$, Slavko Djurašković ${ }^{3}$, Novak Lakićević ${ }^{3}$, Milan Lepić ${ }^{4}$, Andrija Savić ${ }^{1,2}$, Jovan Grujić ${ }^{1,2}$, Aleksa Mićić ${ }^{1}$, Stefan Radojević ${ }^{1}$, Vladimir Puzović ${ }^{5}$, Miloš Maletić ${ }^{1}$ and Stefan Mandić-Rajčević ${ }^{6}$
\end{abstract}

${ }^{1}$ Faculty of Medicine, University of Belgrade, Belgrade, Serbia, ${ }^{2}$ Department of Peripheral Nerve Surgery, Functional Neurosurgery and Pain Management Surgery Clinic for Neurosurgery, University Clinical Center of Serbia, Belgrade, Serbia, ${ }^{3}$ Clinic for Neurosurgery, Clinical Center of Montenegro, Podgorica, Montenegro, ${ }^{4}$ Clinic for Neurosurgery, Military Medical Academy, Belgrade, Serbia, ${ }^{5}$ College of Higher Vocational Studies "Sports Academy", Belgrade, Serbia, ${ }^{6}$ School of Public Health and Health Management and Institute of Social Medicine, Faculty of Medicine, University of Belgrade, Belgrade, Serbia

Radial nerve injuries are often associated with humeral shaft fractures. The results of treatment of these injuries, by contemporary surgical approaches, remain diverse. In this paper we presented the outcomes and analyzed the patient, clinical, and surgical procedure related characteristics and factors that may influence the outcome overall, in 77 patients treated at Clinic for Neurosurgery, Clinical Center of Serbia during a 20 years period. The nerve injuries were verified by US and EMNG. The majority of patients were treated by neurolysis or sural nerve grafting, while only few were treated by direct suture. The final recovery was evaluated by muscle strength assessment and classified using MRC. We analyzed extension of the wrist, extension of the fingers including the thumb, and abduction of the thumb. There was a significant statistical difference in MRC grade following the treatment. The total rate of useful functional recovery was achieved in $69(89.61 \%)$ out of all studied patients, out of whom $20(28.99 \%)$ achieved excellent recovery, 26 (37.68\%) achieved good recovery and 23 (33.33\%) achieved fair recovery. Only 8 (10.39\%) out of all studied patients achieved poor recovery. The injured nerves, that were preserved in continuity, acquired by a low-energy trauma, and treated earlier than the 6 months were associated with better functional outcome following the surgery. In addition, there was a trend of better functional improvement with aging, keeping in mind that the old were subjected to lower energy trauma. The expectant management followed by surgery of radial nerve injury associated with humeral shaft fracture should be around 3 months, and the surgical nerve repair should not be performed later than the 6 months after injury. The energy of trauma may be a factor predicting patient's final recovery following the treatment.

Keywords: radial nerve injuries, humeral shaft fracture, surgical treatment, outcome, neurolysis, grafting 


\section{INTRODUCTION}

The fractures of the humeral shaft make up about $1-3 \%$ of all skeletal fractures, and belong to the group of the most common bone injuries (1-4). The incidence increases with age and may be associated with significant in-patient mortality and health care utilization costs $(2,5-7)$. In addition, the patients remain unable to return to work for a long period even after the surgery $(8,9)$, which is a significant socioeconomic issue (10).

Due to the close topographic ties between nervous, bony and vascular tissues $(1,11)$, the injuries of peripheral nerves are often associated with these injuries (12-14), and radial nerve injuries occur in between 2 and $18 \%$ of cases with humeral shaft fracture (15-19). This high rate of combined injuries is probably due to their close anatomic relation in the spiral groove (sulcus nervi radialis - SNR) at the posterior side of the humeral shaft, as well as due to the rigidity of the radial nerve while piercing the lateral intermuscular septum after exiting the groove (2022). Despite the fact that the fracture repair is usually successful $(23,24)$, the injury to the radial nerve can leave permanent functional disability of the hand (wrist drop) and sequentially the arm as a whole (20). This loss of hand function is found to be a horrifying experience for the majority of patients (25), and the fact that most of the patients contribute significantly to the household and the community further exacerbates their own and their families suffering (26-28) and presents a big socioeconomic issue $(25,29,30)$.

The expert opinions on the timing and necessity of the surgery for associated radial nerve injuries are divided. Some studies suggest that these lesions have a high rate of satisfactory spontaneous recovery $(15,16,31)$, but it may take more than a year for the most of the patients to return to work $(1,32-34)$. Early exploration is only indicated in open fractures $(15,35)$, while the primary nerve repair is only indicated if the nerve has a clean-cut margin, both of which are rare when the nerve is injured by the bone fragments (32).

Based on the contemporary surgical approaches, and a vast personal experience, a clear strategy was developed to treat these patients, and we treated 77 patients during the last 20 years. Beside the outcomes, we aimed to analyze the patient, clinical, and surgical procedure related characteristics and factors that may influence the outcome overall.

\section{MATERIALS AND METHODS}

\section{Patients}

We retrospectively analyzed hospital records in the period from January 1st, 2001 until December 31st, 2020 and found 147 patients with isolated radial nerve lesion, out of whom 77 met below mentioned criteria.

\section{Inclusion Criteria}

- Patients surgically treated during a 20 years period (January 1st, 2001-December 31st, 2020)

- Minimal follow up of 1 year

- Unilateral non-pathological humeral shaft fracture
- Unilateral radial nerve palsy due to humeral shaft fracture or as a consequence of orthopedic management of the fracture

\section{Exclusion Criteria}

- Compressive neuropathy

- Radial nerve injury without associated humeral shaft fracture

- Patients with previous history of peripheral nerve sheath tumor (PNST), demyelinating disorders, or neuropathy due to vasculitis or diabetes mellitus that have acquired humerus fracture and were sent to our clinic for examination

- Patients treated by artificial nerve graft

Before meeting the patients, we made a detailed review of their medical records, and formed a database. All data were re-checked and supplemented in subsequent contacts with the patients.

\section{Clinical Features}

Prior to the surgery, all patients underwent a physical and a complete diagnostic evaluation. Humeral shaft fractures were verified by radiography, while nerve lesions were verified by ultrasonography (US) and neurophysiology, usually the electromyoneurography (EMNG).

To enquire a potential link between patient's characteristics and nerve recovery following the surgery, we considered the age, gender, smoking habits and presence of associated diseases.

TABLE 1 | Combined scale for evaluating final recovery in study patients.

\begin{tabular}{ll}
\hline Poor & MO, M1 and M2 for all muscle groups \\
Fair & M3 for extension of the wrist and fingers; M0, \\
Good & $M 1$, and M2 for thumb abduction \\
Excellent & fingers; M3 for thumb abduction \\
M4 and M5 for all muscle groups
\end{tabular}

Extension of the wrist, extension of the fingers including the thumb, and abduction of the thumb were examined.

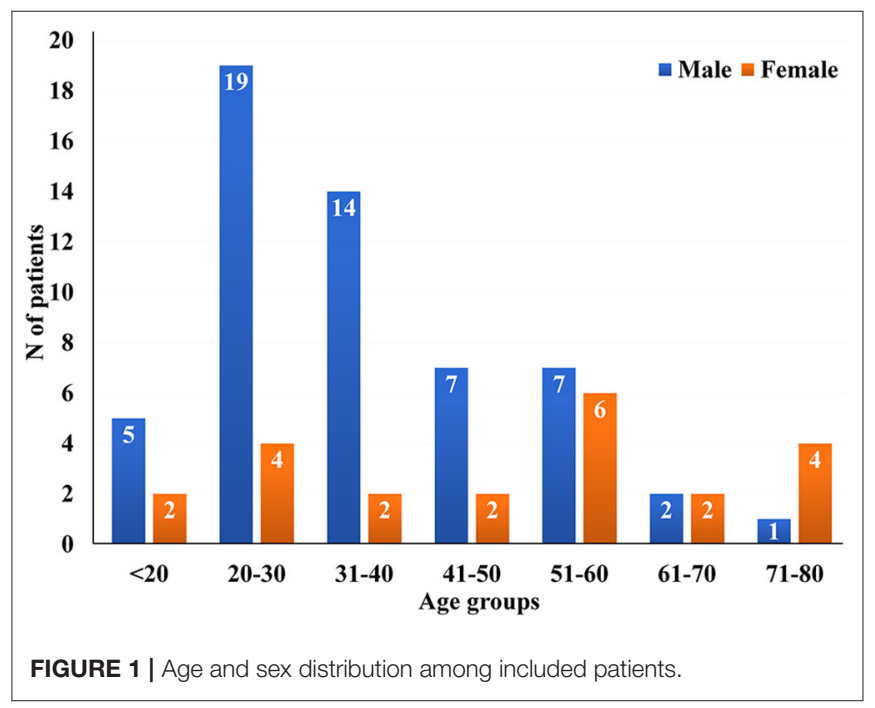


TABLE 2 | Distribution of associated injuries in patients with one, two and multiple associated injuries.

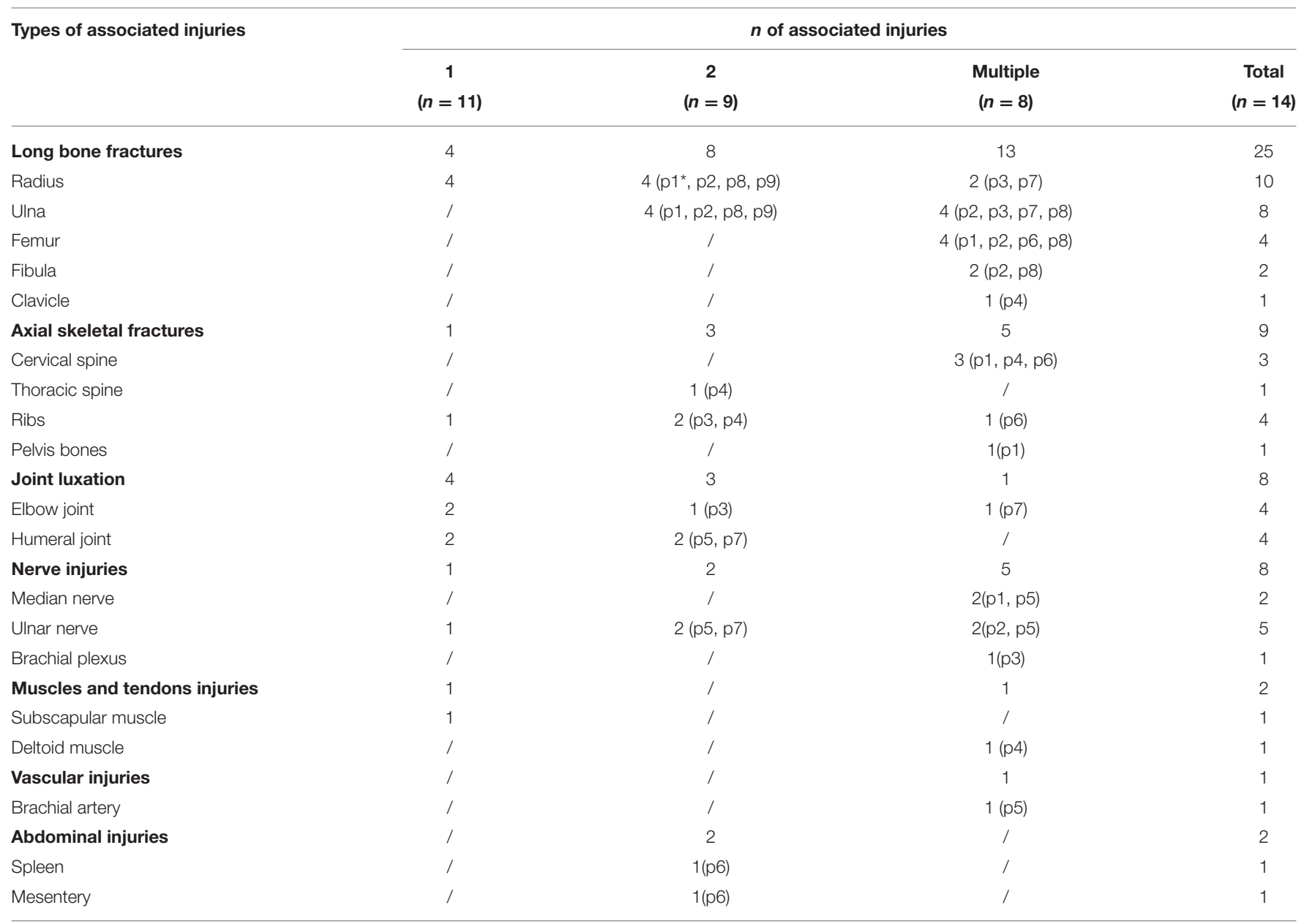

"p1-p9 in the brackets represent injury that occurred in same patient.

The energy of the initial trauma was determined according to the etiology of injury (36): a low-energy trauma (fall from the standing position) and a high-energy trauma (falls from height, traffic accidents, and crushing injuries) and it was previously identified as a prognostic factor that may affect the final recovery (37).

For analyzing how preoperative nerve status affected patient's final recovery, we took into account nature of nerve injury, level of the nerve failure, and continuity of the nerve. Due to insignificant sensory disturbances following radial nerve injury, level of the nerve failure was evaluated by muscle strength assessment and graded according to British Medical Research Council muscle strength scaling system (MRC) (38). We analyzed extension of the wrist, extension of the fingers including the thumb, and abduction of the thumb. The final preoperative result for every single patient was achieved by summarizing MRC scores for all muscles tested.

Humeral shaft fractures were classified based on the level of the fracture line on the shaft (33): D1 (surgical neck fracture), D2 (proximal metaphysis fracture), D3 (fracture of the joint of the proximal and middle third of the body), D4 (fracture of the middle third of the body), D5 (fracture of the junction of the middle and distal third of the body), and D6 (distal metaphysis fracture). In order to analyze how associated injuries affected patient's final recovery, we took into account humerus fracture type and presence of other associated injuries.

\section{Treatment}

The decision-making process and surgical strategy were determined according to the several principles.

Early surgical exploration was indicated in cases with open injuries, or iatrogenic cases with evident (or US confirmed) laceration or compression which were treated as soon as possible. When clear cut margins were present the patient underwent immediate direct suture.

In cases of traumatic nerve palsies associated with closed fracture of the humeral shaft, and iatrogenic nerve palsies without evident cause, a late exploration was indicated.

Following the failure of conservative treatment, after 3 months of expectance for EMNG signs of recovery to appear, the patients were referred to our institution for surgical evaluation and treatment. 
TABLE 3 | Distribution of the study patients in reference to etiology of nerve injury, nature of nerve injury, nerve continuity and level of nerve failure.

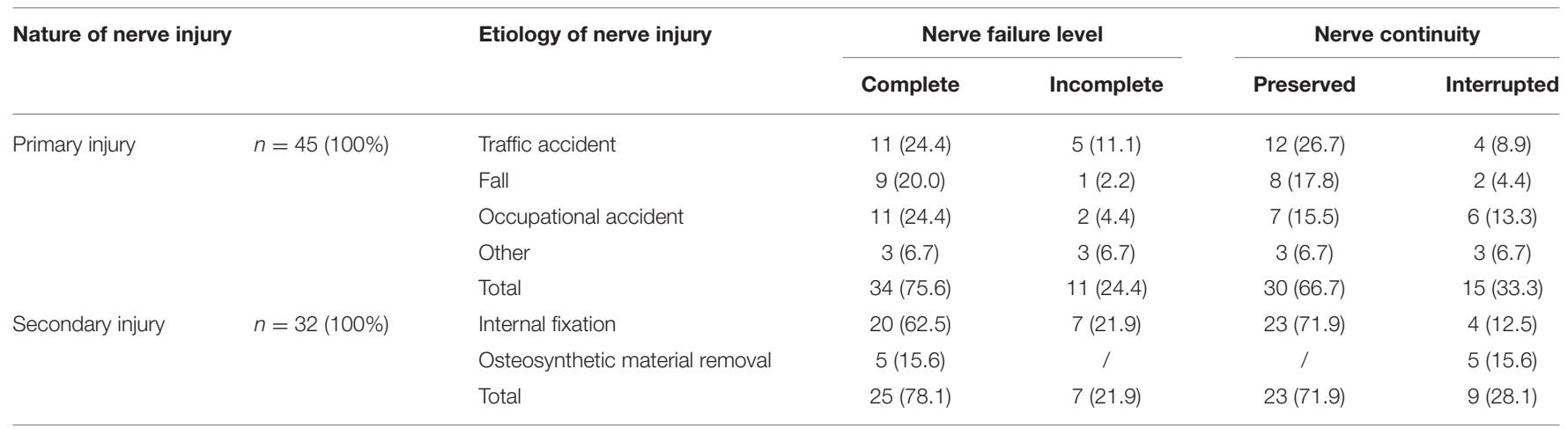

TABLE 4 | Distribution of the study patients in reference to the surgical procedure performed, nature of the nerve injury, level of the nerve failure and time to surgery.

\begin{tabular}{|c|c|c|c|c|c|c|c|c|}
\hline Surgical procedure & \multicolumn{2}{|c|}{ Nature of nerve injury (palsy) } & \multicolumn{2}{|c|}{ Nerve failure level (palsy) } & \multicolumn{4}{|c|}{ Time to treatment (months) } \\
\hline Neurolysis & $30(66.7)$ & $23(71.9)$ & 35 (59.3) & $18(100)$ & 7 & 35 & 3 & 8 \\
\hline Grafting & 13 (28.9) & $9(28.1)$ & 22 (37.3) & I & 1 & 12 & 8 & 2 \\
\hline Total & 45 (100) & $32(100)$ & $59(100)$ & 18 (100) & 9 & 47 & 11 & 10 \\
\hline
\end{tabular}

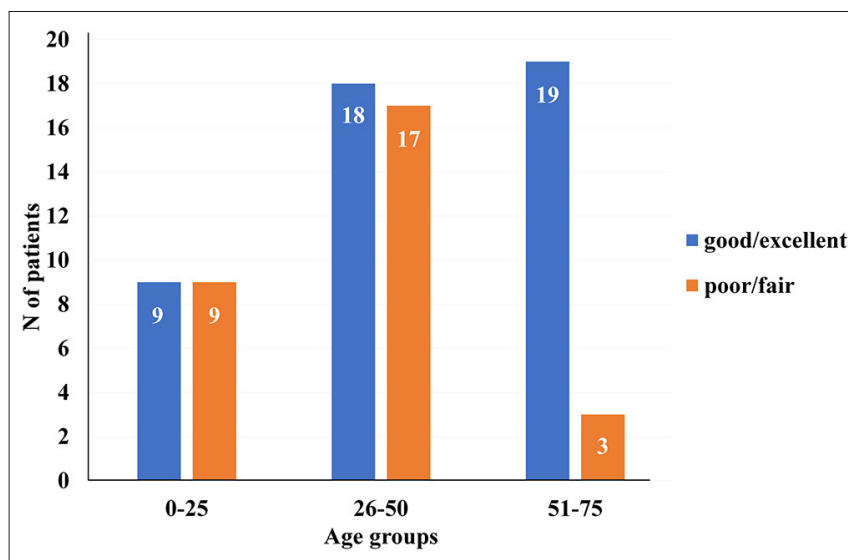

FIGURE 2 | Distribution of the patients in reference to patient's age and patient's final recovery $[x 2(2, N=75)=8.235, p=0.016]$.

This process had not changed much during the last 20 years, and there were no significant variations in treatment of this group of patients.

\section{Outcome Assessment}

The final recovery was evaluated by muscle strength assessment and classified using MRC. The same muscles, tested preoperatively, were tested postoperatively, and the results were compared (total MRC score for all muscle groups tested). The modified scale of Highet and Holmes (Table 1), was used to classify the recovery, and fair or better results were deemed satisfactory $(1,32,39)$.

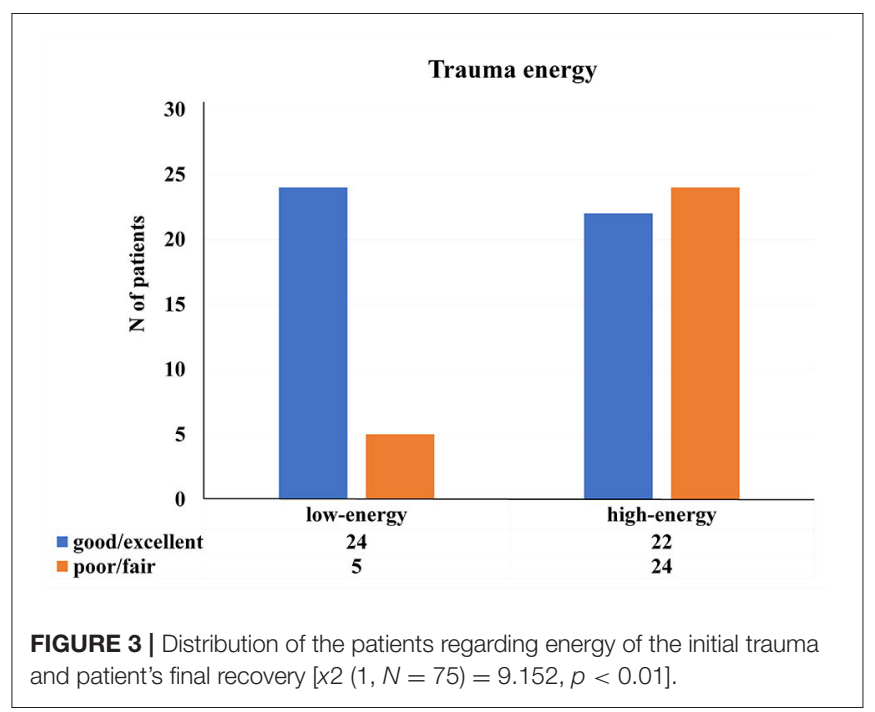

In order to examine how treatment modality and timing affected patient's final recovery, we took into consideration surgical procedures performed as well as the time elapsed until the surgery.

\section{Statistical Analysis}

All statistical procedures were performed using IBM SPSS v26.0. Parameters of interest were described using the methods of descriptive statistics: mean, median, range, absolute $(\mathrm{N})$ and relative (\%) frequencies. The normality of data was assessed using Shapiro-Wilk test. For analyzing the association between patient's groups and patient's final recovery we performed Fisher's 

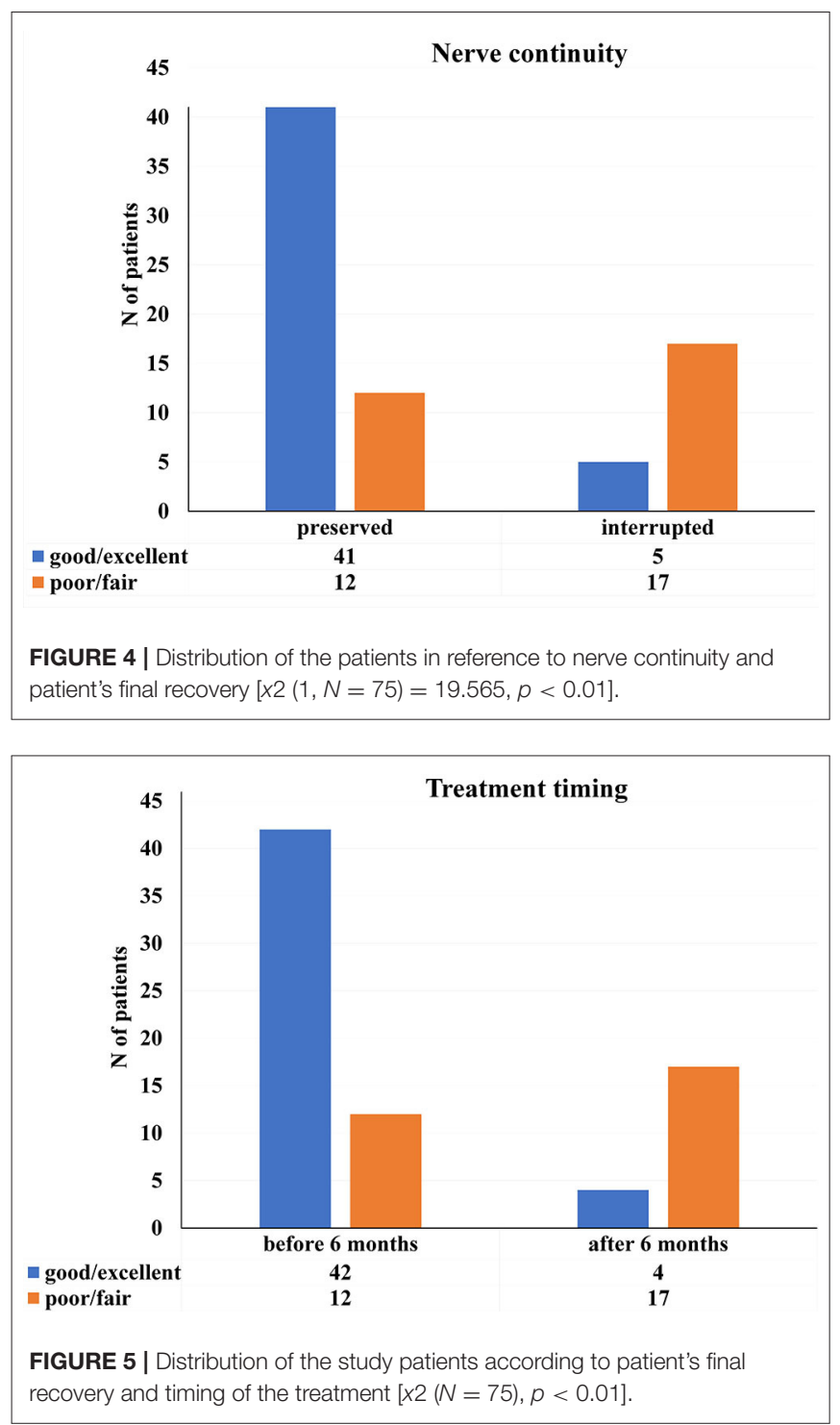

exact and Chi-Square test. For comparing preoperative and postoperative measurements, we used Wilcoxon signed-rank test. The significance factor was set to be lower than 0.05 . Due to low occurrence, the 2 patients treated by direct suture were excluded from the statistical analysis.

For easier statistical analysis of certain factors and characteristics, the patients were divided into the groups: age $(0-25,26-50$, and $51-75$ years old), nature of nerve injury (traumatic/iatrogenic), humerus fracture type (D3 and/or proximally/D4 and/or distally), treatment timing (before 6 months/after 6 months), final recovery (excellent or good/fair or poor).

\section{RESULTS}

Total 55 (71.43\%) male and $22(28.57 \%)$ female patients were in the study group (Figure 1). The mean age was $39.39 \pm 17.10$, while their age ranged from 12 years old to the oldest patient of 75 years old. The mean and median age of male population were $35.38 \pm 14.34$ and $32.0(12-32)$, while the mean and median age of female population were $49.41 \pm 19.56$ and 59.0 (18$75)$, respectively. More than a half of all studied patients -42 $(54.55 \%)$ lived in urban places, while $35(45.45 \%)$ of them lived in rural places.

Out of all studied patients, 31 (40.26\%) were tobacco smokers. Twenty one patients $(27.27 \%)$ had one associated disease, 4 (5.19\%) had two, while 52 (67.53\%) had none.

Concerning the energy of the initial trauma, 46 (59.74\%) patients were subjected to injury by a high-energy trauma (male vs. female $=40: 6$ ), while $31(40.26 \%$ ) patients were subjected to injury by a low-energy trauma (male vs. female $=15: 16$ ). The high-energy trauma was more common in the groups of patients aged $0-25(70.0 \%)$ and $26-50$ (74.29\%), comparing to the group of patients aged 51-75 (27.27\%). Furthermore, all patients with two or multiple associated injuries were subjected to injury by a high-energy trauma (Table 2).

Regarding humeral shaft fracture type, 13 (16.89\%) patients had fracture at the proximal third/middle third junction (D3), $42(54.55 \%)$ patients had fracture at the middle third (D4), 20 (25.97\%) patients had fracture at the middle third/distal third junction (D5), and only $2(2.59 \%)$ patients had fracture at the distal third (D6) of the humeral shaft.

Primary nerve injury occurred in 45 (58.44\%) patients, while secondary (iatrogenic) nerve injury occurred in $32(41.56 \%)$ patients (Table 3). Out of all studied patients, 59 (76.62\%) acquired complete nerve palsy (M0 for all muscle groups), while only $18(23.38 \%)$ acquired incomplete nerve palsy (M1-M3 for all muscle groups).

Most of the patients had the nerve preserved in continuity, and all these patients were treated with neurolysis procedures, while the patients with completely interrupted continuity were subjected to the nerve repair. Out of 53 patients with the nerve preserved in continuity, 35 (66.04\%) were treated by external neurolysis, $10(18.87 \%)$ were treated by longitudinal epineurotomy, and $8(15.09 \%)$ were treated by circumferential epineurectomy and interfascicular neurolysis. Two patients $(8.33 \%)$ had direct nerve suture immediately during the initial exploration of the cut nerve. Other 22 patients (91.67\%) with interrupted continuity underwent grafting. There were no complications related to the nerve surgery. Table 4 shows the distribution of the study patients in reference to the surgical procedure performed, nature of the nerve injury, level of the nerve failure, and time passed to the surgery.

The signs of motor recovery were accomplished in all studied patients. There was a significant increase in MRC grade following surgical treatment $(Z=-7.544, p<0.01)$. The total rate of useful functional recovery was achieved in $69(89.61 \%)$ out of all studied patients, out of whom 20 (28.99\%) achieved excellent recovery, $26(37.68 \%)$ achieved good recovery and 23 (33.33\%) achieved fair recovery. Only $8(10.39 \%)$ out of all studied patients achieved poor recovery.

Regarding patient's characteristics such as gender $(p=0.192)$, smoking habits $(p=0.150)$, and presence of associated diseases $(p=0.065)$, there were no significant statistical differences in patients' final recovery. However, there was a significant difference with reference to patient's age (Figure 2). The excellent 
TABLE 5 | Distribution of the patients in reference to age, treatment timing, nerve continuity and final recovery.

\begin{tabular}{|c|c|c|c|c|c|c|c|c|c|}
\hline \multicolumn{2}{|c|}{$n$ of patients $=77$} & \multicolumn{4}{|c|}{ Poor/fair } & \multicolumn{4}{|c|}{ Good/excellent } \\
\hline & & p.c.* & i.c. ${ }^{* *}$ & p.c. & i.c. & p.c. & i.c. & p.c. & i.c. \\
\hline \multirow[t]{2}{*}{$0-25$} & $<6$ months & / & 2 & / & 2 & 5 & 2 & 2 & I \\
\hline & $>6$ months & 1 & 4 & 2 & / & / & / & / & / \\
\hline \multirow[t]{2}{*}{$51-75$} & $<6$ months & 1 & / & / & 1 & 4 & / & 12 & 1 \\
\hline & $>6$ months & / & 1 & I & / & I & 1 & 2 & I \\
\hline
\end{tabular}

"p.c., preserved continuity; ${ }^{* \star}$ i.c., interrupted continuity.

and good results were more common in the group of patients that were aged 51-75.

As for the concern of energy of the initial trauma, there was a significant statistical difference in patients' final recovery (Figure 3), while, there were no significant differences regarding humerus fracture type $(p=0.801)$ and presence of other associated injuries $(p=0.120)$. The majority of patients subjected to injury by a low-energy trauma-24 $(82.76 \%)$ achieved excellent or good results.

Regarding parameters such as nature of nerve injury ( $p=$ $0.764)$ and level of the nerve failure $(p=0.982)$, there were no significant differences in patient's final recovery following surgery. However, there was a significant difference with reference to continuity of the nerve (Figure 4). The majority of patients with the nerve preserved in continuity-41 (77.36\%) achieved excellent or good results.

Regarding timing of the treatment, there was a significant difference in patients' final recovery between the groups treated earlier and groups treated later than the 6 months since the injury (Figure 5). The most of the patients treated earlier than the 6 months $-42(77.78 \%)$ achieved excellent or good results.

Distribution of the patients regarding age, treatment timing, nerve continuity and final recovery is presented in the Table 5 .

\section{DISCUSSION}

The vary fact that more than a half of radial nerve lesions treated at our clinic during the last 20 years were associated with humeral shaft fracture, indicates the importance of this particular entity.

Recently published studies $(16,18,31,34,35,37,40)$, concerning the outcome in patients with radial nerve injury associated with humeral shaft fracture, have used different inclusion and exclusion criteria comparing to our study. Most of these studies included only conservatively treated patients (16, 18,31 ), while some of them included only complete nerve failures $(34,35,37)$, or only primary nerve injuries due to humerus fracture $(18,31)$. The studies that included both surgically and conservatively treated patients were mainly concentrated on determining the best indication for early nerve exploration and repair $(34,35,40)$. Therefore, it was difficult to compare all these results with each other, as well as with the results of our study. However, we were able to compare the results of our study with the results of two other studies $(1,32)$, which have also included only surgically treated patients and have evaluated patient's final recovery using MRC muscle scale.

According to the published literature (41-44), the aging influences morphologic and functional features of the peripheral nerves, which may alter final regeneration and recovery of the nerves. However, according to our results, there was a trend of improved functional recovery with aging. Although apparently misleading, the older population is more cautious, and the trauma is usually a low-energy event $(45,46)$, therefore, the injury as well as eventual surgery is less extensive, and with better recovery potential. Contributing to this are the results of the study by Joseph et al. (47) which have revealed that age, as an independent factor, was not predictive of functional outcome after injury.

The most of our younger patients were subjected to injury by a high-energy trauma, which was associated with poorer final recovery. A poorer final recovery in patients subjected to injury by a high-energy trauma has also been shown in another study conducted over the same subject, and according to those authors (37) it may be caused by the extensive zone of tissue injury.

The quality of functional recovery was better in patients with the injured nerve preserved in continuity compared to the interrupted cases, which is in accordance with the results of previous studies (20, 48-50).

Regarding previous studies, concerning associated humeral shaft fractures and radial nerve injuries $(1,32,35)$, in case of no indications for primary exploration, the expectant management of nerve injury followed by surgical treatment should last for 3-4 months, and the treatment should not be performed later than 5-6 months (51). We agree with these recommendations, and therefore, we treated most of our patients in the period between 3 and 6 months. We were not able to perform early exploration in all situations where it was indicated $(1,32,35)$, because many of our patients lived in rural places, and it took more time for these patients to be referred to our institution, as local physicians were not always aware of recent indications for closed injuries. Regarding the 9 patients treated earlier than the 3 months since the injury, 2 of them had the nerve with clean-cut margins, which was an indication for primary nerve repair, 3 had the nerve compressed by a plate, and 4 others had an immediate radial nerve palsy following conservative treatment by other 
specialists, confirmed by clinical and EMNG findings. However, some of our patients were treated later than the 6 months since the injury, which may be also due to different place of patient's residence, as well as due to different extent of patient's injury and number of other associated injuries. The cause of eventual later management of nerve injuries in the patients who lived in rural places might be due to difficulties for general practitioners to diagnose peripheral nerve injuries, and therefore it takes more time for those patients to be referred to our institution. The cause of eventual later management of nerve injuries in all patients may be due to polytrauma and delayed deployment of these patients from the institutions responsible for the care of bone fractures $(1,52)$.

The results of our study regarding the total rate of useful functional recovery are comparable with the results of previous studies $(1,32)$ that have used modified Highet's scale in order to qualitative describe patient's final recovery. Despite the fact that rate of useful functional recovery in patients with the nerve preserved in continuity was similar, the rate of useful functional recovery in patients with the nerve interrupted in continuity was lower in our study comparing to the results of aforementioned studies $(1,32)$. The differences in these results may be due to different length of the nerve gap, as well as due to different energy of the initial trauma.

Considering that, in their study, neither of these authors presented energy of the trauma, we emphasize the importance of presenting it and considering it as a prognostic factor that may predict patients' final recovery following surgery.

\section{REFERENCES}

1. Rasulić L, Samardzić M, Bascarević V, Jovanović M, Malis M, Nikolić $\mathrm{V}$, et al. Current trends in surgical treatment of radial nerve injuries associated with injuries of the humerus. Acta Chir Iugosl. (2010) 57:7780. doi: 10.2298/ACI1001077R

2. Ekholm R, Adami J, Tidermark J, Hansson K, Törnkvist H, Ponzer S. Fractures of the shaft of the humerus. An epidemiological study of 401 fractures. J Bone Jt Surg Ser B. (2006) 88:1469-73. doi: 10.1302/0301-620X.88B11.17634

3. Tytherleigh-Strong G, Walls N, McQueen MM. The epidemiology of humeral shaft fractures. J Bone Jt Surg Ser B. (1998) 80:249-53. doi: 10.1302/0301-620X.80B2.0800249

4. Biber R, Bail HJ, Geßlein M. Humeral shaft fractures. Unfallchirurg. (2018) 121:747-58. doi: 10.1007/s00113-018-0533-4

5. Maravic M, Briot K, Roux C. Burden of proximal humerus fractures in the French National Hospital Database. Orthop Traumatol Surg Res. (2014) 100:931-4. doi: 10.1016/j.otsr.2014.09.017

6. Fjalestad T, Hole M, Jørgensen JJ, Strømsøe K, Kristiansen IS. Health and cost consequences of surgical versus conservative treatment for a comminuted proximal humeral fracture in elderly patients. Injury. (2010) 41:599-605. doi: 10.1016/j.injury.2009.10.056

7. Rosas S, Kurowicki J, Yee T, Momoh E, Kalandiak SP, Levy JC. Cost of treatment for proximal humerus fractures: an acute and 90day cost evaluation. J Long Term Eff Med Implants. (2018) 28:1739. doi: 10.1615/JLongTermEffMedImplants.2018027815

8. Kumbaraci M, Basa CD, Turgut A. Analysis of factors affecting return to work after surgical treatment in patients with $\mathrm{AO}$ type $\mathrm{C}$ distal humerus fractures. Indian J Orthop. (2020) 55:680-7. doi: 10.1007/s43465-020-00260-x

9. Dietrich M, Wasmer M, Platz A, Spross C. Return-to-work following open reduction and internal fixation of proximal humerus fractures. Open Orthop J. (2014) 8:281-7. doi: 10.2174/1874325001408010281

\section{CONCLUSION}

The expectant management followed by surgery of radial nerve injury associated with humeral shaft fracture should be around 3 months, and the surgical nerve repair should not be performed later than the 6 months after injury. The energy of trauma may be a factor predicting patient's final recovery following the treatment.

\section{DATA AVAILABILITY STATEMENT}

The original contributions presented in the study are included in the article/supplementary material, further inquiries can be directed to the corresponding author/s.

\section{ETHICS STATEMENT}

The studies involving human participants were reviewed and approved by Ethics Committee of the Faculty of Medicine, university of Belgrade. The patients/participants provided their written informed consent to participate in this study.

\section{AUTHOR CONTRIBUTIONS}

All authors contributed to the preparation of this manuscript. The manuscript has been seen and approved by all authors.

10. O'Hara NN, Isaac M, Slobogean GP, Klazinga NS. The socioeconomic impact of orthopaedic trauma: a systematic review and meta-analysis. PLoS ONE. (2020) 15:1-22. doi: 10.1371/journal.pone.0227907

11. Topal AE, Eren MN, Celik Y. Lower extremity arterial injuries over a sixyear period: outcomes, risk factors, and management. Vasc Health Risk Manag. (2010) 6:1103-10. doi: 10.2147/VHRM.S15316

12. Franz RW, Skytta CK, Shah KJ, Hartman JF, Wright ML, A. five-year review of management of upper-extremity arterial injuries at an urban level I trauma center. Ann Vasc Surg. (2012) 26:655-64. doi: 10.1016/j.avsg.2011.11.010

13. Troupis TG, Michalinos A, Manou V, Vlastos D, Johnson EO, Demesticha $\mathrm{T}$, et al. Report of an unusual combination of arterial, venous and neural variations in a cadaveric upper limb. J Brachial Plex Peripher Nerve Inj. (2014) 9:e10-15. doi: 10.1186/1749-7221-9-2

14. Rasulic L, Cinara I, Samardzic M, Savic A, Zivkovic B, Vitosevic F, et al. Nerve injuries of the upper extremity associated with vascular trauma-surgical treatment and outcome. Neurosurg Rev. (2017) 40:2419. doi: 10.1007/s10143-016-0755-2

15. Shao YC, Harwood P, Grotz MRW, Limb D, Giannoudis P V Radial nerve palsy associated with fractures of the shaft of the humerus. A systematic review. J Bone Jt Surg Ser B. (2005) 87:1647-52. doi: 10.1302/0301-620X.87B12.16132

16. Belayneh R, Lott A, Haglin J, Konda S, Leucht P, Egol K. Final outcomes of radial nerve palsy associated with humeral shaft fracture and nonunion. $J$ Orthop Traumatol. (2019) 20:18. doi: 10.1186/s10195-019-0526-2

17. Ilyas AM, Mangan JJ, Graham J. Radial nerve palsy recovery with fractures of the humerus: an updated systematic review. J Am Acad Orthop Surg. (2020) 28:e263-9. doi: 10.5435/JAAOS-D-18-00142

18. Ostermann RC, Lang NW, Joestl J, Pauzenberger L, Tiefenboeck TM, Platzer P. Fractures of the humeral shaft with primary radial nerve palsy: do injury mechanism, fracture type, or treatment influence nerve recovery? J Clin Med. (2019) 8:1969. doi: 10.3390/jcm8111969 
19. Heckler MW, Bamberger HB. Humeral shaft fractures and radial nerve palsy: to explore or not to explore that is the question. Am J Orthop. (2008) 37:415-9.

20. Ljungquist KL, Martineau P, Allan C. Radial nerve injuries. J Hand Surg Am. (2015) 40:166-72. doi: 10.1016/j.jhsa.2014.05.010

21. Ozden H, Demir A, Guven G, Yildiz Zeki Z, Turgut A, Bulbul K, et al. The relation of sulcus nervi radialis with the fracture line of humerus fracture and radial nerve injury. Surg Radiol Anat. (2009) 31:2837. doi: $10.1007 / \mathrm{s} 00276-008-0444-0$

22. Kim DH, Kam AC, Chandika P, Tiel RL, Kline DG. Surgical management and outcome in patients with radial nerve lesions. J Neurosurg. (2001) 95:57383. doi: 10.3171/jns.2001.95.4.0573

23. Zhao JG, Wang J, Meng XH, Zeng XT, Kan SL. Surgical interventions to treat humerus shaft fractures: a network meta-analysis of randomized controlled trials. PLoS ONE. (2017) 12:1-12. doi: 10.1371/journal.pone.0173634

24. Solberg BD, Moon CN, Franco DP, Paiement GD. Surgical treatment of three and four-part proximal humeral fractures. J Bone Jt Surg Ser A. (2009) 91:1689-97. doi: 10.2106/JBJS.H.00133

25. Rasulić LG, Puzović V, Rotim K, Jovanović M, SamardŽić M, Živković B, et al. The epidemiology of forearm nerve injuries - a retrospective study. Acta Clin Croat. (2015) 54:19-24.

26. Puzović V, SamardŽić M, Jovanović M, Živković B, Savić A, Rasulić LG. Etiology and mechanisms of ulnar and median forearm nerve injuries. Vojnosanit Pregl. (2015) 72:961-7. doi: 10.2298/VSP140818106P

27. Bergmeister KD, Große-Hartlage L, Daeschler SC, Rhodius P, Böcker A, Beyersdorff M, et al. Acute and long-term costs of 268 peripheral nerve injuries in the upper extremity. PLoS ONE. (2020) 15:1-12. doi: 10.1371/journal.pone.0229530

28. Jaquet J, Luijsterburg AJM, Kalmijn S, Kuypers PDL, Hofman A. Hovius SER. Funct Outcome Return Prod. (1997) 51:68792. doi: 10.1097/00005373-200110000-00011

29. Rosberg HE, Carlsson KS, Dahlin LB. Prospective study of patients with injuries to the hand and forearm: costs, function, and general health. Scand J Plast Reconstr Surg Hand Surg. (2005) 39:360-9. doi: 10.1080/02844310500340046

30. Dias JJ, Garcia-Elias M. Hand injury costs. Injury. (2006) 37:10717. doi: 10.1016/j.injury.2006.07.023

31. Ekholm R, Ponzer S, Törnkvist H, Adami J, Tidermark J. Primary radial nerve palsy in patients with acute humeral shaft fractures. J Orthop Trauma. (2008) 22:408-14. doi: 10.1097/BOT.0b013e318177eb06

32. SamardŽić M, Grujičić D, Milinković ZB. Radial nerve lesions associated with fractures of the humeral shaft. Injury. (1990) 21:220-2. doi: 10.1016/0020-1383(90)90006-G

33. Nachef N, Bariatinsky V, Sulimovic S, Fontaine C, Chantelot C. Predictors of radial nerve palsy recovery in humeral shaft fractures: a retrospective review of 17 patients. Orthop Traumatol Surg Res. (2017) 103:17782. doi: 10.1016/j.otsr.2016.10.023

34. Ring D, Chin K, Jupiter JB. Radial nerve palsy associated with high-energy humeral shaft fractures. J Hand Surg Am. (2004) 29:144-7. doi: 10.1016/j.jhsa.2003.09.013

35. Korompilias AV, Lykissas MG, Kostas-Agnantis IP, Vekris MD, Soucacos PN, Beris AE. Approach to radial nerve palsy caused by humerus shaft fracture: is primary exploration necessary? Injury. (2013) 44:3236. doi: 10.1016/j.injury.2013.01.004

36. Stein H, Hoerer WD, Lerner A, Rozen N, Nierenberg G. Musculoskeletal trauma: high- and low-energy injuries. Orthopedics. (1999) 22:9657. doi: 10.3928/0147-7447-19991001-14

37. Venouziou AI, Dailiana ZH, Varitimidis SE, Hantes ME, Gougoulias NE, Malizos KN. Radial nerve palsy associated with humeral shaft fracture. Is the energy of trauma a prognostic factor? Injury. (2011) 42:128993. doi: 10.1016/j.injury.2011.01.020

38. Wang Y, Sunitha M, Chung KC. How to measure outcomes of peripheral nerve surgery. Hand Clin. (2013) 29:349-61. doi: 10.1016/j.hcl.2013. 04.004
39. Amillo S, Barrios RH, Martínez-Peric R, Losada JI. Surgical treatment of the radial nerve lesions associated with fractures of the humerus. J Orthop Trauma. (1993) 7:211-5. doi: 10.1097/00005131-199306000-00002

40. Schwab TR, Stillhard PF, Schibli S, Furrer M, Sommer C. Radial nerve palsy in humeral shaft fractures with internal fixation: analysis of management and outcome. Eur J Trauma Emerg Surg. (2018) 44:23543. doi: 10.1007/s00068-017-0775-9

41. Wagstaff LJ, Gomez-Sanchez JA, Fazal SV, Otto GW, Kilpatrick AM, Michael K, et al. Failures of nerve regeneration caused by aging or chronic denervation are rescued by restoring schwann cell c-jun. Elife. (2021) 10:132. doi: $10.7554 /$ eLife. 62232

42. He L, Yadgarov A, Sharif S, McCluskey LP. Aging profoundly delays functional recovery from gustatory nerve injury. Neuroscience. (2012) 209:208-18. doi: 10.1016/j.neuroscience.2012.02.012

43. Verdú E, Ceballos D, Vilches JJ, Navarro X. Influence of aging on peripheral nerve function and regeneration. J Peripher Nerv Syst. (2000) 5:191208. doi: $10.1046 / j .1529-8027.2000 .00026 . x$

44. Scheib J, Höke A. Impaired regeneration in aged nerves: clearing out the old to make way for the new. Exp Neurol. (2016) 284:7983. doi: 10.1016/j.expneurol.2016.07.010

45. Chehade M, Gill TK, Visvanathan R. Low energy trauma in older persons: where to next? Open Orthop J. (2015) 9:3616. doi: $10.2174 / 1874325001509010361$

46. Gowing R, Jain MK. Injury patterns and outcomes associated with elderly trauma victims in Kingston, Ontario. Can J Surg. (2007) 50:437-44.

47. Joseph B, Pandit V, Aziz H, Tang A, Kulvatunyou N, Wynne J, et al. Rehabilitation after trauma; does age matter? J Surg Res. (2013) 184:5415. doi: 10.1016/j.jss.2013.03.069

48. Rasulić L, Lepić M, Savić A, Lepić T, SamardŽić M. Peripheral nervous sy surgery: travelling through no man's land to new horizons. Neurol India. (2019) 67:9-15. doi: 10.4103/0028-3886.250732

49. Lundborg G. A 25-year perspective of peripheral nerve surgery: evolving neuroscientific concepts and clinical significance. J Hand Surg Am. (2000) 25:391-414. doi: 10.1053/jhsu.2000.4165

50. Menorca RMG, Fussell TS, Elfar JC. Nerve physiology. Mechanisms of injury and recovery. Hand Clin. (2013) 29:317-30. doi: 10.1016/j.hcl.2013. 04.002

51. DeFranco MJ, Lawton JN. Radial nerve injuries associated with humeral fractures. J Hand Surg Am. (2006) 31:655-63.doi: 10.1016/j.jhsa.2006.02.013

52. Rasulić L, Savić A, Vitošević F, SamardŽić M, Živković B, Mićović $\mathrm{M}$, et al. Iatrogenic peripheral nerve injuries-surgical treatment and outcome: 10 years' experience. World Neurosurg. (2017) 103:841-51.e6. doi: 10.1016/j.wneu.2017.04.099

Conflict of Interest: The authors declare that the research was conducted in the absence of any commercial or financial relationships that could be construed as a potential conflict of interest.

Publisher's Note: All claims expressed in this article are solely those of the authors and do not necessarily represent those of their affiliated organizations, or those of the publisher, the editors and the reviewers. Any product that may be evaluated in this article, or claim that may be made by its manufacturer, is not guaranteed or endorsed by the publisher.

Copyright (ㅇ 2021 Rasulić, Djurašković, Lakićević, Lepić, Savić, Grujić, Mićić, Radojević, Puzović, Maletić and Mandić-Rajčević. This is an open-access article distributed under the terms of the Creative Commons Attribution License (CC BY). The use, distribution or reproduction in other forums is permitted, provided the original author(s) and the copyright owner(s) are credited and that the original publication in this journal is cited, in accordance with accepted academic practice. No use, distribution or reproduction is permitted which does not comply with these terms. 